\title{
A new fuzzy-dynamic risk and reliability assessment
}

\author{
Majid Vaziri Sarashk ${ }^{\mathrm{a}^{*}}$, Sohrab Khanmohammadi ${ }^{\mathrm{b}}$ and Mahmood Alborzi ${ }^{\mathrm{a}}$
}

\begin{abstract}
${ }^{a}$ Department of Management and Economy, Islamic Azad University, Science and Research Branch, Tehran, Iran ${ }^{b}$ Faculty of Electrical and Computer Engineering, University of Tabriz, Tabriz, Iran

CHRONICLE ABSTRACT

Article history:

Received October 15, 2014

Accepted January 24, 2014

Available online

February 12014

Keywords:

Failure modes and effects analysis

Reliability management

Systems and control theory

Fuzzy logic

System dynamics approach
\end{abstract}

\section{Introduction}

Failure mode and effect analysis (FMEA) is an important technique used to detect and to eliminate known or potential failures to enhance the reliability and safety of complex systems and it is intended to provide information for making appropriate risk management decisions. In order to analyze a specific product or system, a cross-functional team needs to be established for carrying out FMEA first. The first step in FMEA is to detect all potential failure modes of the products using systematic brainstorming. A critical analysis is then executed on these failure modes to detect the risk factors including occurrence $(\mathrm{O})$, severity $(\mathrm{S})$ and detection $(\mathrm{D})$. The purpose of FMEA is to rank the failure modes of the product or system in order to assign the limited resources to the most important risk factors.

\footnotetext{
* Corresponding author.

E-mail addresses: m_sarashk@yahoo.com (M. Vaziri Sarashk)

(C) 2014 Growing Science Ltd. All rights reserved.

doi: $10.5267 /$ j.dsl.2014.2.001
} 
Normally, the prioritization of failure modes for corrective actions is prepared through the risk priority number (RPN) obtained by detecting the multiplication of the $\mathrm{O}, \mathrm{S}$ and $\mathrm{D}$ of a failure as follows,

$\mathrm{RPN}=\mathrm{O} \times S \times D$,

where $O$ represents the probability of the failure, $S$ denotes the severity of the failure, and $D$ is determines the probability of not detecting the failure. For obtaining the RPN of a potential failure mode, we evaluate the three risk factors based on the 10-point scale. The higher the RPN implies the bigger product/system reliability. With respect to the scores of RPNs, the failure modes can be ranked and then proper actions will be preferentially taken on the high-risk failure modes. RPNs should be recalculated after making some corrections to see whether the risks are lowered or not. We also make sure to check the efficiency of the corrective action for each failure mode. However, the conventional RPN method has been criticized extensively in the literature for a variety of reasons explained in next section. With respect to this review, the innovation of this study is more released.

\section{Literature Review}

FMEA, first was developed as a formal design methodology in the 1960s by the aerospace industry ( Pelaez \& Bowles, 1996) and it has proven to be a useful and powerful tool in assessing potential failures and preventing unwanted incidents (Sankar \& prabhu, 2001). FMEA is an analysis technique to define, to identify and to eliminate known and/or potential failures, problems, errors and so on from system, design, process and/or service before they reach the customer (Stamatis, 2003). When it is used for a criticality analysis, it is also referred to as failure mode, effects and criticality analysis (FMECA). The primary objective of FMEA is to identify potential failure modes, to evaluate the causes and effects of various component failure modes, and to detect what could eliminate or reduce the chance of failure. The results of the analysis can help analysts identify and correct the failure modes, which have special impact on the system and to improve its performance during the stages of design and production. FMEA has been extensively used in a wide range of industries, including aerospace, automotive, nuclear, electronics, chemical, mechanical and medical technologies industries (Chang et al., 2011; Chin et al., 2008; Sharma \& Sharma, 2010).

Traditionally, risk assessment in FMEA is performed by developing a risk priority number (RPN). Nevertheless, the crisp RPN method incorporates some important weaknesses when FMEA is applied for some real-world problems. The major shortcomings of FMEA are:

1-The relative importance of different components of $O, S$ and $D$ is not taken into account.

2-Different combinations of $O, S$ and $D$ may produce precisely the same value of RPN, but their hidden risk implications may be totally different.

3- It is often a tedious task to evaluate all three risk factors.

4- The mathematical formula for calculating RPN is under question.

5- The conversion of scores is different for the three risk factors.

6- The RPN cannot be applied to measure the effectiveness of corrective actions.

7- RPNs are not continuous with many holes.

8- Interdependencies among various failure modes and effects are not taken into account.

9- The mathematical form adopted for calculating the RPN is strongly sensitive to variations in risk factor evaluations. 
10- The RPN elements have several duplicated numbers.

11- The RPN considers only three risk factors mainly in terms of safety.

Therefore, many alternative approaches have been suggested in the literature to resolve some of the shortcomings of the traditional RPN method and to implement FMEA into real-world circumstance, more efficiently. This section provides a review of those academic works trying to tackle with problems in the traditional RPN method and to classify the existing literature by the approaches implemented. Furthermore, those articles that report on a method or technique that specifically aims at overcoming some of the drawbacks of the traditional FMEA. This implies that related articles merely explaining the FMEA process or applying the traditional FMEA have not been included.

The methods used in the literature are divided into five main categories presented in Table 1. This review not only provides evidence that some alternate approaches are better than the traditional RPN approach, but also aids the researchers and risk analysts in implementing the FMEA, more effectively. The results are derived from applying FMEA directly influence on reliability, while this only theoretically is pointed by researchers and in practical scope has been not surveyed. Doing these as the most important problems in field of system reliability is challenging issue in this study.

\section{Table 1}

Classification of risk evaluation methods in FMEA

\begin{tabular}{|c|c|c|}
\hline Categories & Approaches & Literature \\
\hline MCDM & $\begin{array}{l}\text { ME-MCDM; Evidence theory; AHP/ANP; } \\
\text { Fuzzy TOPSIS; Grey theory; DEMATEL; } \\
\text { Intuitionistic fuzzy set; Ranking technique } \\
\text { VIKOR }\end{array}$ & $\begin{array}{l}\text { Franceschini \& Galetto, 2004, 2005; Chin et al., 2009b; } \\
\text { Chin et al., 2011; Braglia et al., 2003b; Seyed-Hosseini et } \\
\text { al., 2006; Chang et al., 2010; Liu et al., } 2012\end{array}$ \\
\hline $\begin{array}{l}\text { Mathematical } \\
\text { programming }\end{array}$ & Linear programming; DEA/Fuzzy DEA & Wang et al., 2009b; Garcia et al., 2005 \\
\hline $\begin{array}{l}\text { Artificial } \\
\text { intelligence }\end{array}$ & $\begin{array}{l}\text { Rule-base system; Fuzzy rule-base system; } \\
\text { Fuzzy ART algorithm; Fuzzy cognitive } \\
\text { map }\end{array}$ & $\begin{array}{l}\text { Sankar \& prabhu, 2001; Pelaez \& Bowles, 1996; } \\
\text { Guimaraes et al., 2004, 2006, } 2007\end{array}$ \\
\hline $\begin{array}{l}\text { Integrated } \\
\text { approaches }\end{array}$ & $\begin{array}{l}\text { Fuzzy AHP-Fuzzy rule-base system } \\
\text { WLSM-MOI-partial ranking method } \\
\text { OWGA operator-DEMATEL } \\
\text { Fuzzy OWA operator-DEMATEL } \\
\text { IFS-DEMATEL } \\
\text { 2-tuple-OWA operator } \\
\text { FER-Grey theory } \\
\text { Fuzzy AHP-Fuzzy TOPSIS } \\
\text { ISM-ANP-UPN }\end{array}$ & $\begin{array}{l}\text { Chang et al., 1999, 2001; Pillay \& Wang, 2003; Xu et al., } \\
2002\end{array}$ \\
\hline $\begin{array}{l}\text { Other } \\
\text { approaches }\end{array}$ & $\begin{array}{l}\text { Kano model } \\
\text { Probability theory }\end{array}$ & $\begin{array}{l}\text { Shahin, 2004; Shahin \& Zairi, 2009; Sant'Anna \& } \\
\text { Sant'Anna, 2008; Ben-Daya \& Raouf, 1996; Grosh, } 1982\end{array}$ \\
\hline
\end{tabular}

\section{Suggested methodology}

The methodology used in this study is composed of two separable sections. The first section is associated with system's transfer functions and the second section describes how to calculate the parameters.

\subsection{Estimation of transfer function (TF)}

The problem of system's identifying is concentrated on determining its transfer function (TF), which is the operation that a system does on its inputs to receive output. If TF is determined, then output (system's response) with respect to various inputs by using of convolution integral and properties of Laplace transform is obtained, i.e. $X(t)=\int_{0}^{t} U(\tau) G(t-\tau) d \tau=U(s) G(s)$. On the other words, if 
input is unit step and TF is determined at frequency domain then Laplace transform of output will be: $\mathrm{U}(\mathrm{s}) \mathrm{G}(\mathrm{s})=\mathrm{X}(\mathrm{s})$. Inverse Laplace transform of above equation is equivalent to $\mathrm{X}(\mathrm{t})$, where $\mathrm{X}(\mathrm{t})$ is system's step response and shows the state of system at every instant of time. As an example, there are many cases where increasing time results in failures. Therefore, risk change at start point $(\mathrm{O})$ is maximum and when time increases it trends to zero. Fig. 1 shows details of such system.

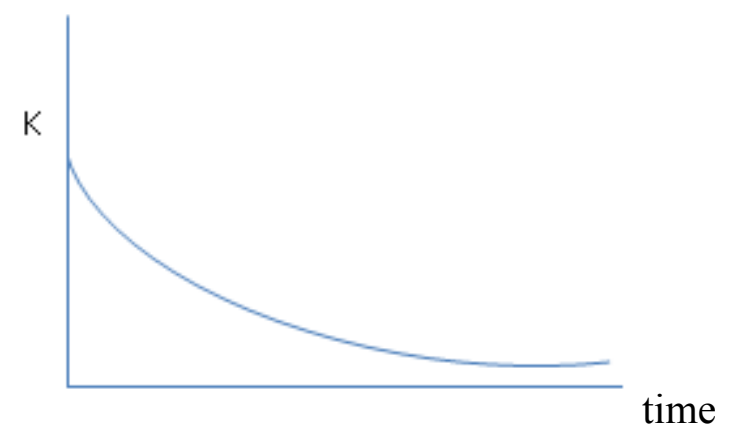

Fig. 1. Time response of risk change, w.r.t time

Systems with such behavior shown in Fig. 1 have TF in form of $G(s)=\frac{k \tau s}{1+\tau s}$ where $\mathrm{k}$ is a parameter, which represents velocity of cause's unit impact, $\tau$ is a parameter represents effecting time (equivalent with system's time constant) and $s$ is Laplace variable, i.e. $s=j+\sigma \omega$. Because input is unit step and its Laplace is $\frac{1}{s}$ so Laplace transform of output is as follows,

$$
X(s)=\frac{1}{s} \times \frac{k \tau s}{1+\tau s}=\frac{k \tau}{1+\tau s} .
$$

Therefore, the inverse Laplace transform is as follows,

$X(t)=k e^{-\frac{t}{\tau}}$

Normalized behavior is: $\frac{X(t)}{k}=e^{-\frac{t}{\tau}}$ and Table 2 presents states of the system.

Table 2

Calculating states of the system

\begin{tabular}{|c|c|c|c|c|c|c|c|c|c|}
\hline$\frac{t}{\tau}$ & 0 & 1 & 2 & 3 & 4 & 4.6 & 5 & $\ldots \ldots$ & $\infty$ \\
\hline$\frac{x(t)}{k}$ & 1 & .368 & .135 & .05 & .18 & .01 & .007 & $\ldots \ldots$ & 0 \\
\hline
\end{tabular}

According to Table 2, when $\frac{t}{\tau} \geq 4.6$, the system reaches $99 \%$ of its steady state. This time is named settling time to one percent of steady state. So, time to failure $(T)$ is assumed as $T=5 \tau$. Using similar procedure, time response of failure rate is calculated. Transfer function for failure rate function is as follows,

$G(s)=\frac{k \omega_{n}^{2}}{s^{2}+2 \zeta \omega_{n} s+\omega_{n}^{2}}$

where $K$ is the average that system finally follows and is representing system's steady state response, i.e. $k=\frac{1}{T}$ such that $T=5 \tau, \zeta$ is damping ratio that is determined based on parameters of risk controlling signal obtained in previous stage $(\mathrm{k} \& \tau)$. In addition, $\omega_{n}$ is natural frequency of system that is equal with: $\omega_{n}=\frac{2 \pi}{T}$. Parameters of the transfer functions are calculated by using fuzzy inference systems (FIS) explained, next. 


\subsection{Fuzzy assessment methodology}

In this study, we use three FIS, where the first FIS and the second one have similar inputs, i.e. O, D and Dependency. The output of FIS1 is $K$ and for the FIS2 is $\tau$ used to for risk's transfer function. In next stage, $K \& \tau$ will be as inputs of FIS3 such that the output is $\zeta$. In every stage, inputs are fuzzified using appropriate membership functions to determine degree of membership in each input class. The resulting fuzzy inputs are evaluated in fuzzy inference engine, which makes use of welldefined rule base consisting of if-then rules and fuzzy logic operations to determine output level of the every FIS. The fuzzy conclusion is then defuzzified to get crisp values for outputs at various FIS levels so that transfer functions related to quantities (risk and failure rate) can be evaluated, accordingly. Finally, the unit step responses of the systems are calculated by using of convolution integral and properties of Laplace transform explained in section 3.1. The fuzzy linguistic assessment model was developed using toolbox platform of MATLAB 6.5 R.13. To represent input and output variables in FIS, graphically, triangular and trapezoidal membership functions (Figs. 2-4) are used, which are consistent with the definitions of the variables used in the study as depicted in Tables 3-6.

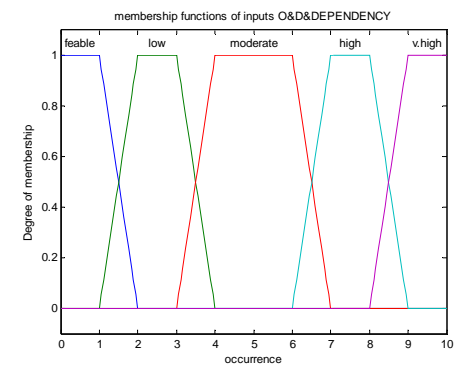

Fig. 2. Fuzzy membership functions for inputs of FIS1 \& FIS2

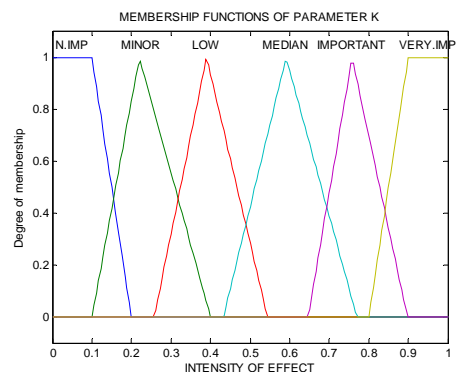

Fig. 3. Fuzzy membership functions for outputs of FIS1 \& FIS2

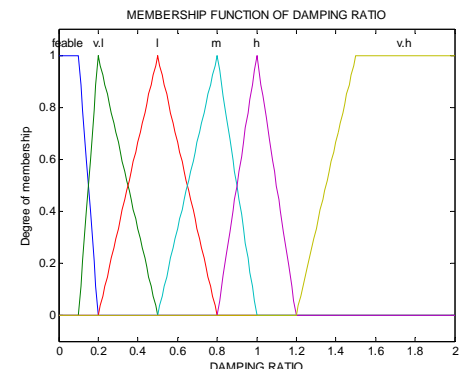

Fig. 4. Fuzzy membership functions for output of FIS3

The descriptive terms explaining the dependency membership functions are Feeble, Low, Moderate, High and very high.

\section{Table 3}

Scales used to measure probability of failure occurrence

\begin{tabular}{lllc}
\hline Descriptive assessment of probability of failure & Mean time between failures & Score & Occurrence rate $(\%)$ \\
\hline Feeble & $>5$ years & 1 & $<0.01$ \\
Low & $2-5$ years & $2-3$ & $0.01-0.1$ \\
Moderate & $1-2$ years & $4-6$ & $0.1-0.5$ \\
High & $3-6$ months & $7-8$ & $0.5-1$ \\
Very high & $<3$ months & $9-10$ & $>1$ \\
\hline
\end{tabular}

\section{Table 4}

Scales used to determine probability of non-detection

\begin{tabular}{lcc}
\hline Non-detection & Score & Likelihood of non-detection $(\%)$ \\
\hline Feeble & 1 & $0-5$ \\
Low & 2 & $6-15$ \\
& 3 & $16-25$ \\
Moderate & 4 & $26-35$ \\
& 5 & $36-45$ \\
High & 6 & $46-55$ \\
& 7 & $56-65$ \\
Very high & 8 & $66-75$ \\
& 9 & $76-85$ \\
\hline
\end{tabular}




\section{Table 5}

Scales used for parameters $\mathrm{k} \& \tau$ assessment

\begin{tabular}{lll}
\hline Rank no. & Effect on risk change (time \& magnitude effect) & Meaning \\
\hline $0-0.1$ & Not important (N.IMP) & Less MTTR $>1$ hour \\
$0.11-0.25$ & Minor (M) & MTTR $>1$ day \\
$0.26-0.50$ & L & MTTR 1-4 days \\
$0.51-0.60$ & Median (ME) & MTTR4-8days \\
$0.61-0.80$ & Important (IMP) & External intervention for repairs \\
$0.81-1$ & Very important (V.IMP) & Line shut down or production loss \\
\hline
\end{tabular}

Table 6

Scales used for damping ratio assessment

\begin{tabular}{lll}
\hline Descriptive assessment of damping ratio & Time to failure & Score \\
\hline V.L & Very short & $0-0.2$ \\
L & Short & $0.21-0.8$ \\
M & Median & $0.81-1.4$ \\
V.H & Long & $1.2-2.0$ \\
\hline
\end{tabular}

\section{Case study}

To demonstrate the application of proposed approach for implementing the proposed method, a case study from an industrial firm is considered. There are many functional units in this case, while it is decided to conduct failure mode analysis of the main functioning unit i.e. piston's seat exfoliation operation. Two potential failure modes are released: 1- Increasing seat's diagonal and 2- Decreasing distance from piston's seat to piston's bottom. The cause of first mode is unregulated tool and for second is wobbling snip in system.

For the first cause input data is obtained: $\mathrm{O}=8, \mathrm{D}=9$ and Dependency $=6$

For the second cause, data is obtained: $\mathrm{O}=5, \mathrm{D}=3$ and Dependency $=4$

By using of two fuzzy inference systems, parameters of TF for the first cause will be $\mathrm{K}=.768$ and $\tau=.24$. In addition, parameters of $\mathrm{TF}$ for the second cause will be $\mathrm{K}=.5$ and $\tau=.5$. The mapping of inputs to the outputs through the linguistic if-then rules adopted in the study is represented using a control surface plot (Fig. 5). Since in the study three inputs have been used, so the surface plot can be represented with a group of surfaces keeping one of the input variables stable. In this study, one figure is shown for example. The rest of figures also have similar behaviors.

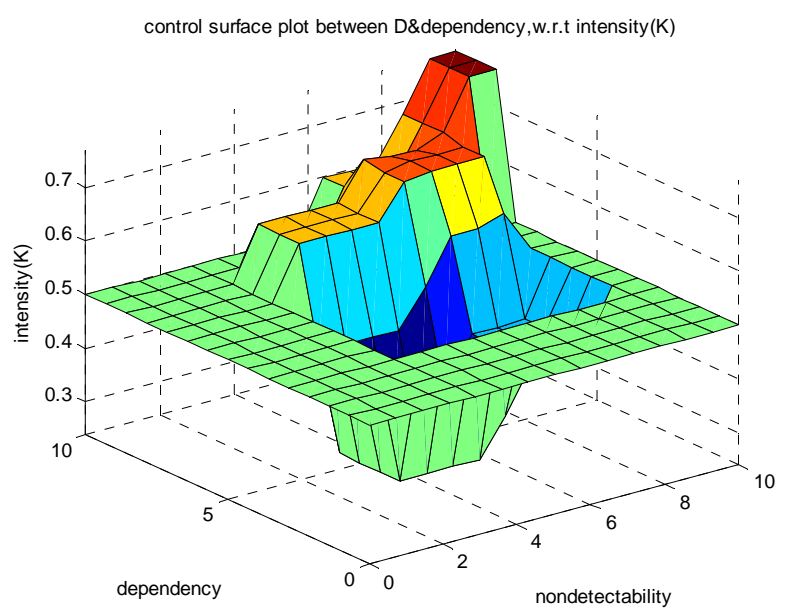

Fig. 5. Control surface plot between (D) \& (Dep), w.r.t K 
These three-dimensional plots represent very well the systems used to in this study. Obtained values for $\mathrm{K} \& \tau$ are used as the inputs of the third FIS. For the first cause is calculated $\zeta=.268$ and for the second cause $\zeta=.536$. Then, by using of the procedure detailed in the section 3-1 failure rate function for the first failure will be:

$$
\lambda(t)=.83\left\{1-e^{-1.41 t} \cos 5.04 t+.28 \sin 5.04 t\right\},
$$

and for the second failure is as follows,

$\lambda(t)=.4\left\{1-e^{-1.34 t} \cos 2.1 t+.64 \sin 2.1 t\right\}$

The corresponding figures for calculated $\lambda(t) s$ is shown in Fig. 6 and Fig. 7, respectively. It is pointed out that, this special case is composed of two failure modes, so failure rate for the corresponding operation is summation of two functions calculated before, i.e.

$\lambda_{s}(t)=\lambda_{1}(t)+\lambda_{2}(t)$

On the other hand, relation between failure rate and reliability functions is:

$R(t)=e^{-\int_{0}^{T} \lambda(t) d t}$

Therefore, in this case reliability is as shown in Fig. 8.

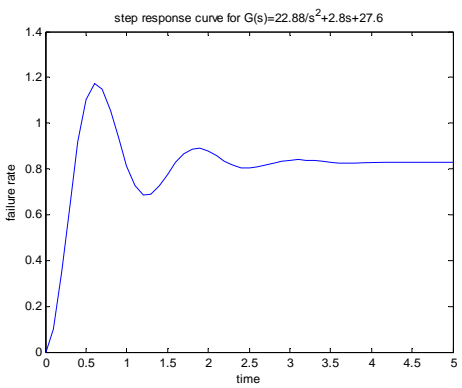

Fig. 6. Failure rate function for the first failure

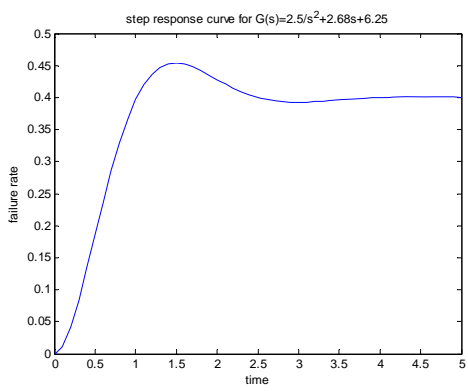

Fig. 7. Failure rate function for the second failure

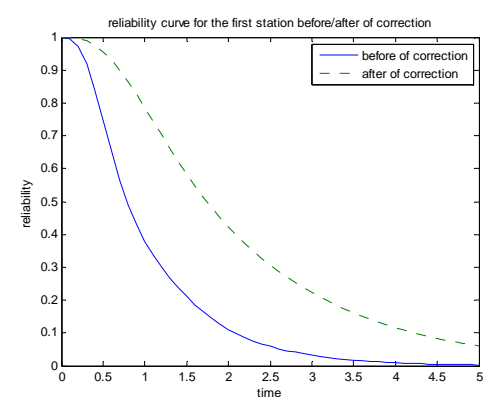

Fig. 8. The impact of corrective action (feedback) on reliability

With respect to Fig. 6 and Fig. 7, because of lower settling time for the first cause, it was decided that first cause selected for corrective actions. Reliability after of correction is as shown in figure 8 by dashed line (--). It is concluded from Fig. 8 that in every instant of time reliability after correction is bigger than before correction. This is due to feedback factor in system.

\section{Conclusions}

We have presented a new method for risk assessment in FMEA method based on fuzzy technique. The proposed study of this paper has tried to use linguistic numbers to handle uncertainty associated with different components of FMEA methodology. The proposed study has been implemented for a case study and the results have been discussed. In addition, this study shows that integrating of fuzzy logic-based approach and system dynamics methodology resolve the limitations associated with traditional method for RPN evaluation of failure causes in reliability analysis of system.

\section{Acknowledgement}

The authors would like to thank the anonymous referees for constructive comments on earlier version of this paper. 


\section{References}

Ben-Daya, M., \& Raouf, A. (1996). A revised failure mode and effects analysis model. International Journal of Quality \& Reliability Management, 13(1), 43-47.

Braglia, M., Frosolini, M., \& Montanari, R. (2003). Fuzzy criticality assessment model for failure modes and effects analysis. International Journal of Quality \& Reliability Management, 20(4), 503-524.

Chang, C. L., Wei, C. C., \& Lee, Y. H. (1999). Failure mode and effects analysis using fuzzy method and grey theory. Kybernetes, 28(9), 1072-1080.

Chang, C. L., Liu, P. H., \& Wei, C. C. (2001). Failure mode and effects analysis using grey theory. Integrated Manufacturing Systems, 12(3), 211-216.

Chin, K. S., Chan, A., \& Yang, J. B. (2008). Development of a fuzzy FMEA based product design system. The International Journal of Advanced Manufacturing Technology, 36(7-8), 633-649.

Franceschini, F., \& Galetto, M. (2004). An empirical investigation of learning curve composition laws for quality improvement in complex manufacturing plants. Journal of Manufacturing Technology Management, 15(7), 687-699.

Franceschini, F., Galetto, M., \& Varetto, M. (2005). Ordered samples control charts for ordinal variables. Quality and Reliability Engineering International,21(2), 177-195.

Grosh, D. L. (1982). A parallel system of CFR units is IFR. Reliability, IEEE Transactions on, 31(4), 403-403.

Guimaraes, A. C., \& Franklin Lapa, C. M. (2004). Effects analysis fuzzy inference system in nuclear problems using approximate reasoning. Annals of nuclear Energy, 31(1), 107-115.

Pillay, A., \& Wang, J. (2003). Modified failure mode and effects analysis using approximate reasoning. Reliability Engineering \& System Safety, 79(1), 69-85.

Sant'Anna, L. A., \& Sant'Anna, A. P. (2008). A probabilistic approach to evaluate the exploitation of the geographic situation of hydroelectric plants. Energy Policy, 36(7), 2320-2329.

Sankar, N. R., \& Prabhu, B. S. (2001). Modified approach for prioritization of failures in a system failure mode and effects analysis. International Journal of Quality \& Reliability Management, 18(3), 324-336.

Seyed-Hosseini, S. M., Safaei, N., \& Asgharpour, M. J. (2006). Reprioritization of failures in a system failure mode and effects analysis by decision making trial and evaluation laboratory technique. Reliability Engineering \& System Safety,91(8), 872-881.

Sharma, R. K., \& Sharma, P. (2010). System failure behavior and maintenance decision making using, RCA, FMEA and FM. Journal of Quality in Maintenance Engineering, 16(1), 64-88.

Shahin, A. (2004). Integration of FMEA and the Kano model: An exploratory examination. International Journal of Quality \& Reliability Management, 21(7), 731-746.

Shahin, A., \& Zairi, M. (2009). Kano model: a dynamic approach for classifying and prioritising requirements of airline travellers with three case studies on international airlines. Total Quality Management, 20(9), 1003-1028.

Stamatis, D. H. (2003). Failure mode and effect analysis: FMEA from theory to execution. Asq Press.

Wang, K. S., \& Wan, E. H. (1993). Reliability consideration of a flexible manufacturing system from fuzzy information. International Journal of Quality \& Reliability Management, 10(7). 30-44

Xu, K., Tang, L. C., Xie, M., Ho, S. L., \& Zhu, M. L. (2002). Fuzzy assessment of FMEA for engine systems. Reliability Engineering \& System Safety, 75(1), 17-29.

Zadeh, L. A. (1965). Fuzzy sets. Information and Control, 8, 338-353. 